\title{
Implementation of Automatic Transfer Switch on the Solar Home System at the Goat Farm Houses
}

\author{
Anna Nur Nazilah Chamim*1, Agil Peggy Irawan ${ }^{1}$, Ramadoni Syahputra $^{1}$ \\ ${ }^{1}$ Department of Electrical Engineering, Universitas Muhammadiyah Yogyakarta \\ Jl. Lingkar Selatan, Tamantirto, Kasihan, Yogyakarta, Indonesia \\ *Corresponding author, e-mail: anna_nnc@umy.ac.id
}

\begin{abstract}
In Pirak Mertosutan Hamlet, Sleman, Yogyakarta, there is a goat farm complex with about $600 \mathrm{~m}^{2}$. The intricate lighting comes from the National Electricity Company (PLN) and the Solar Home System (SHS). SHS is the primary energy source for lighting, while PLN is a secondary energy source that replaces it when the power supply from SHS goes out. So far, the transfer from SHS to PLN has been carried out by humans. This fact is considered inefficient because the SHS supply does not always die during the day. At night, the officers who move the difficulties have to go to the cage complex located relatively far from residential areas. To facilitate the transfer of energy sources from SHS to PLN and vice versa. It does not need to be done by officers. It is necessary to automatically install a means to automatically move the two sources automatically. This tool is the Automatic Transfer Switch (ATS). This tool can move the energy supply from SHS to PLN and vice versa. By considering the specifications used in the SHS in the farm complex, the ATS is made and then installed in the farm complex. After the installation is carried out, the functional test is carried out. The ATS installation test results show that the ATS can work according to the design; namely, when the SHS is off, the source used is automatically switched to PLN. When the SHS is on, the source that was using PLN will automatically switch to SHS.
\end{abstract}

Keywords: Automatic transfer switch, solar home system, goat farmhouses

\section{Introduction}

The use of renewable energy sources in Indonesia is becoming increasingly popular [1]. One of the renewable energy generators that are widely used is solar home system (SHS) [2]-[4]. Some Indonesians have used SPP to supply electricity for their daily needs. One of the SPP users is the community that manages animal farms. In Pirak Hamlet, Sidoluhur Village, Godean District, Sleman Regency, Yogyakarta Special Region Province, there is a goat farming group called Marsudi Luhur. This farmer focuses on cultivating ettawa goats. This farmer has a cage complex covering an area of 600 square meters. To light the cage complex using two sources of electrical energy, namely from PLN and solar home system (SHS).

The energy source comes from SHS used as the primary energy source, while the reserve energy source comes from PLN. Of the two energy sources used for lighting, there is a problem; namely, moving from one energy source to another is still operating manually so that when the electricity goes out, the operator is required to move the distribution from the primary source to a backup source. To overcome the problems in this herd, a system is designed to automatically change the distribution path of electrical energy from primary electrical power to backup electrical energy [5]-[6].

This study aims to design a solar home system equipped with an automatic transfer switch (ATS). This ATS function replaces the source of electrical energy as a power supply to the goat farm location, from the SHS source to PLN or vice versa. The results of this system design have been implemented at the goat farm location. The performance of SHS equipped with ATS has been analyzed comprehensively [7]-[8]. 


\section{Literature Study}

\section{II.1 Related Research}

There have been many studies related to Automatic Transfer Switch (ATS), but the research conducted by the author has its specificity. Other researchers who have focused on ATS include Saputro [9]. This research discusses how making ATS and AMF and finding out how the working principles that occur in ATS and AMF so that when ATS and AMF are completed, the hope is that it can make it easier to operate the generator automatically without operator intervention. Another researcher working in the same field is Majid [10]. In his study, it discusses the design and analysis of the work system of ATS by considering the capacity, as well as utilizing solar energy sources as alternative energy.

Furthermore, Hidayat et al. [11] conducted designing a single-phase ATS with a maximum customer power limit of 4400 VA. This study discusses the design of a system that can provide electrical energy continuously to meet the needs of household electrical energy customers, designing an automatic device for transferring energy supply from primary power to reserve energy or preferably. This study describes how to make tools, namely ATSAMF panels, with affordable manufacturing costs. Asriyadi et al. [12] conducted a design of Automatic Transfer Switch (ATS) in SHS and PLN and Genset. This research discusses an ATS-AMF control system design that automatically regulates the flow of electrical energy from PV and battery, PLN and generator using Circuit Breakers, Magnetic Contactor (MCs), relays, timers. The initial stage in making ATS/AMF begins with developing the ATS/AMF Algorithm, then continues with the ATS/AMF hardware design, and the last step is testing the ATS/AMF hardware.

\section{II.2. Solar Home System with Automatic Transfer Switch}

Indonesia has a huge area, consisting of thousands of islands scattered from the west to the east. The large area for electrical energy needs is managed by a state company named PLN. PLN is one of the stateowned enterprises in the electricity supply sector in Indonesia. Electricity in Indonesia began to increase in the 19th century when Dutch companies only used electricity for production purposes.
Currently, the use of renewable energy is increasingly popular in Indonesia, one of which is solar power. Solar power plants are one of the producers of electrical energy by utilizing renewable natural resources in solar energy. In addition, the power generation system is used for lighting and electrical energy needs. The components in a solar power plant are solar cells, solar charge controllers, batteries, inverters.

An electric panel is a tool used to regulate, disconnect and share electrical energy. The electric panel usually also contains information about electrical energy such as voltage, current and voltage frequency. The components that are common in an ATS electrical panel are as follows: Indicator light, Relay, Time Delay Relay (TDR), Magnetic contactor, Mini Circuit Breaker (MCB), and cable.

The indicator light on the ATS panel is one of the components on the ATS panel, which functions as an indicator to indicate a system is running or not. Relay is an electronic component that functions as a connecting switch or circuit breaker whose working system uses an electromagnetic system. Fig. 1 shows a typical of relay.

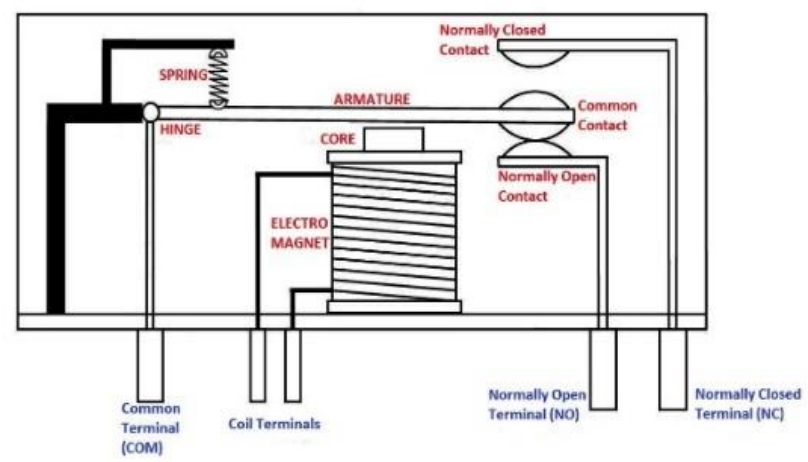

Fig. 1. Typical of relay

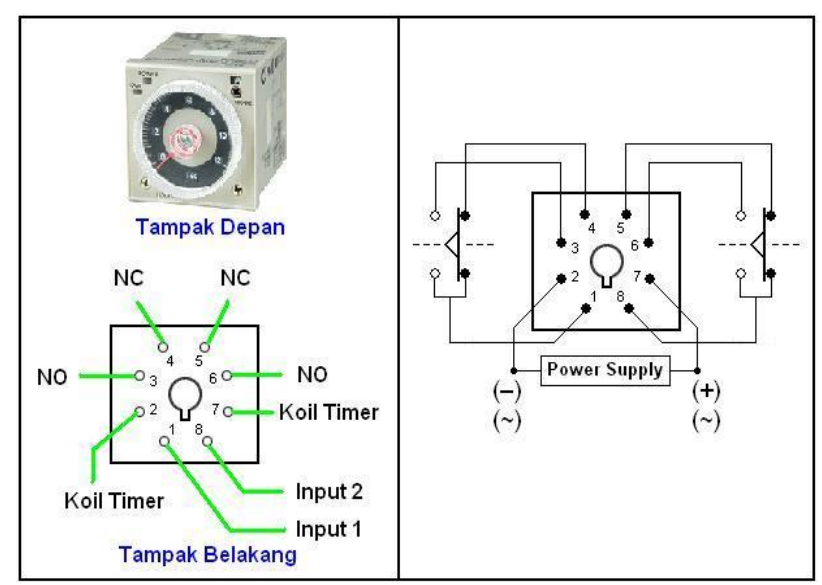

Fig. 2. Typical of time delay relay (TDR) 
Time delay relay, commonly abbreviated as TDR, is an electrical component whose work system is similar to a relay, namely TDR works with an electromagnetic system. Fig. 2 shows a typical of time delay relay (TDR). A magnetic contactor is a type of switch that works according to the electromagnetic principle. MCB is one of the electrical components that function as an overcurrent protection. This component is essential for use in electrical systems. MCB is most often used in household electrical installations. Usually, MCB is placed on bottom of a KWH meter. A cable is one of the essential components of an electrical system. A cable is a medium for transmitting electrical energy.

\section{Methodology}

The steps in this research are shown in Fig. 3. The first step is literature study. At this stage, a search for previous research is carried out, then look for the characteristics, working principles of each component that will be used, and the provisions in the design process.

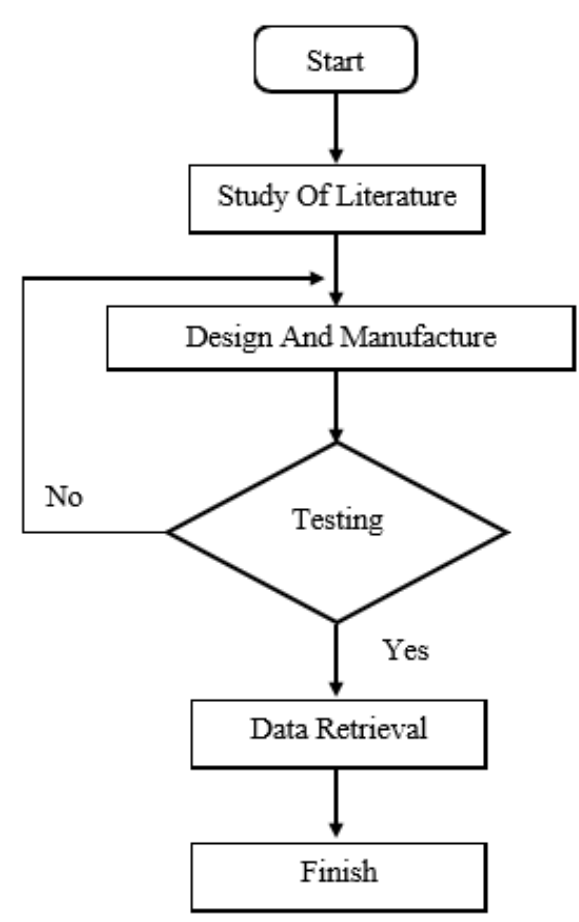

Fig. 3. Flowchart of the research step

The next step is the design and assembly of the tools. The activities carried out are collecting data, making block diagrams, determining components, designing wiring systems, and making box designs. After the design of the tool has been formed perfectly, it is tested. Tests are carried out to ensure that the system can actually work and is in accordance with what was designed. The next step is data collection. The purpose of collecting this data is to determine the system's response to be designed and the system's reliability is made. Data retrieval can also be one of the determining variables whether the system can work properly or not.

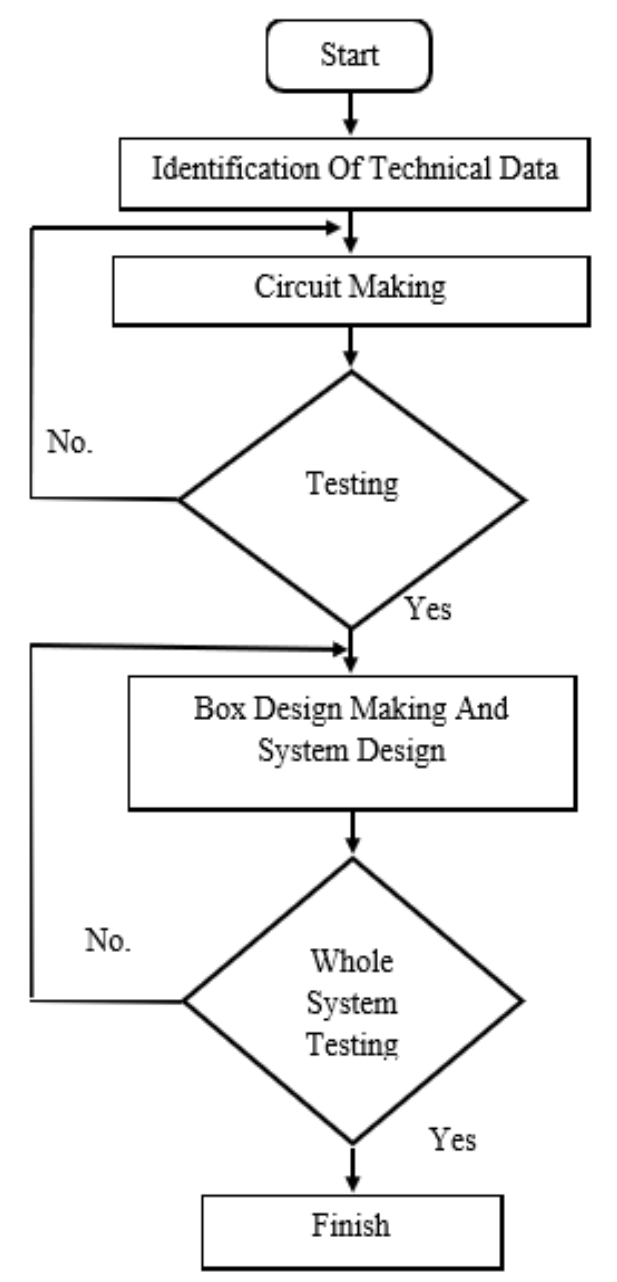

Fig. 4. Flowchart of the testing scenario

Fig. 4 shows the flowchart of the testing scenario in this research. The first step is to identify technical data. Identification of this data is done by serving directly to the place where the system will be made. The identification of technical data is taken data which includes the energy source used then calculating the load used, observing the placement of the system to be made. Used later, and determine the system requirements that will be used. The source of electrical energy that will be utilized is an energy source from SHS with a capacity of 200 watts peak and a source from PLN with an electric power capacity of $900 \mathrm{VA}$. 
The electricity load in the sublime Marsudi farm complex in the Godean sub-district is the lighting load which consists of 4 LED lamps with a power capacity of 10 Watt for each lamp used.

Tests are carried out on the software and directly whether the circuit is running well and according to the research needs. If the series has problems, the series will be regenerated to correct the existing constraints.

An important step in this research is designing the box and the whole system. To determine the panel box design, it must be based on the number of components used, the environment where the panel is placed, the ease of operation of the panel, and making cable lines on the panel box. After finishing designing the box, the next step is to design the system that has been created in the process of making the circuit for the box that has been designed. In the design process, it does not always go well. There is the possibility of errors in the wiring system design process on the box panel.

The stage of testing the entire system is the final stage in the process of making this system. This is because the design process does not always go well. There is a possibility of an error in the wiring system design process on the panel box, so it is indispensable to do a test to ensure the system can run properly.

\section{Results and Discussion}

\section{IV.1 Design of Automatic Transfer Switch}

In designing an automatic transfer switch (ATS), it is essential to design a wiring circuit. The wiring circuit image serves to understand the work function of each component. It becomes a reference for an engineer to benefit from system assembly because, in the circuit picture, there is a system wiring system.

Fig. 5 shows a single line diagram of ATS system. A single line diagram is a series of pictures consisting of a single-pole chart depicting the electrical system and the components used from the source of electrical energy to load. This single line diagram is made to make it easier for an engineering technician to understand the electrical system and the functions of each component involved.

The security system in this ATS system only uses the MCB as a security system to secure all components of the automatic transfer switch system and to secure loads from short circuits and overloads. The function of the relay in the system is essential, namely, as a regulator of the current energy source path so that it can determine which TDR will work, while the function of this TDR is to connect the energy source from the source. Besides that, the TDR also functions as a pause to prepare the inverter to work stably before the load is fed by the inverter so that it can reduce the risk of damage to the inverter faster.

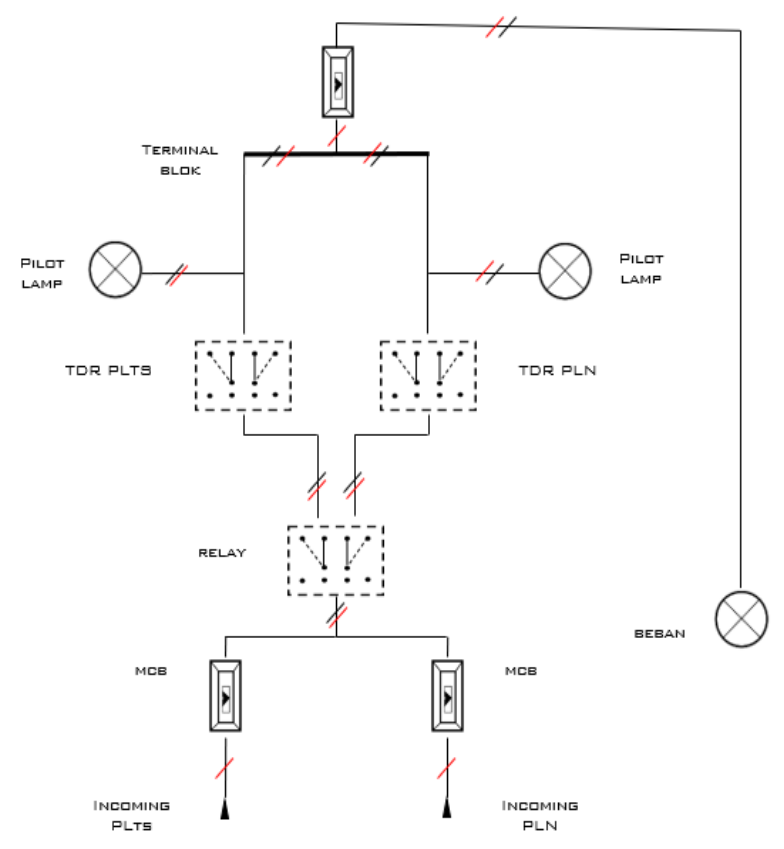

Fig. 5. Single line diagram of ATS system

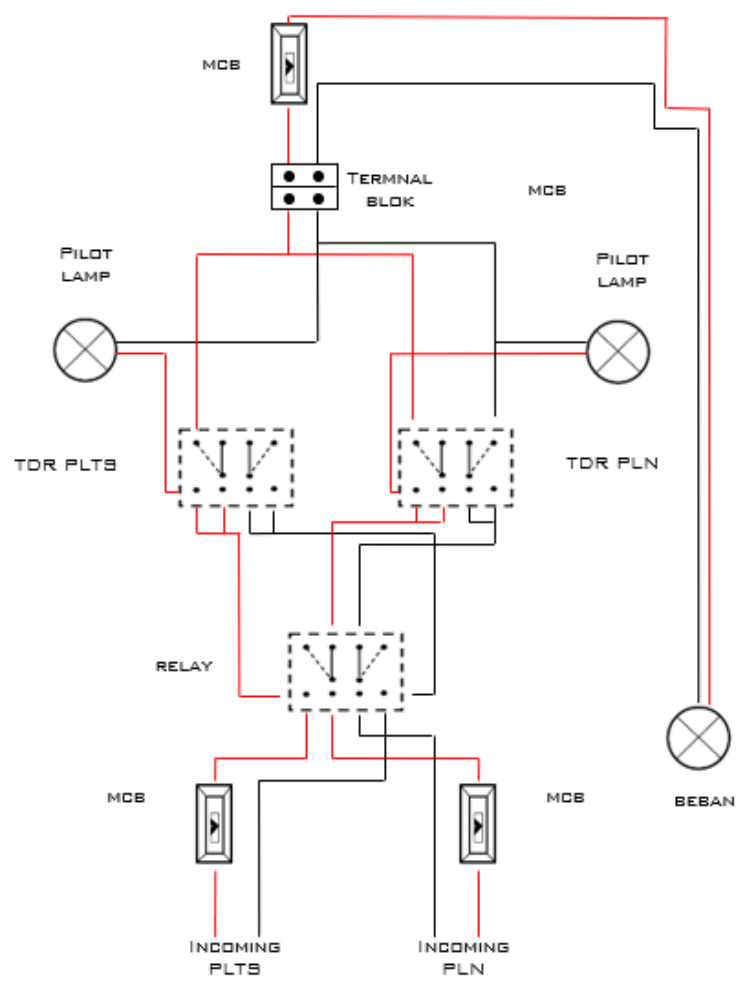

Fig. 6. Single line diagram of ATS system 
The indicator light serves as an indicator to find out which source of electrical energy is functioning and can be an indicator if there is damage to the system, making it easier to carry out system repairs.

The wiring circuit diagram is a description of the wiring circuit in a system designed with simple component symbols. This circuit diagram can be said to be an actual wiring circuit to combine each component in the system being designed.

\section{IV.2 Simulation and Testing of Automatic Transfer Switch}

Before doing the actual testing in the field, a simulation is carried out first. Simulations are carried out using special software. In addition, simulations are also carried out manually if in the simulation process using the appropriate software. The software used in the ATS sequence simulation process is the Festo fluidSIM software. Fig. 7 shows the diagram of ATS system in Festo fluidSIM software.
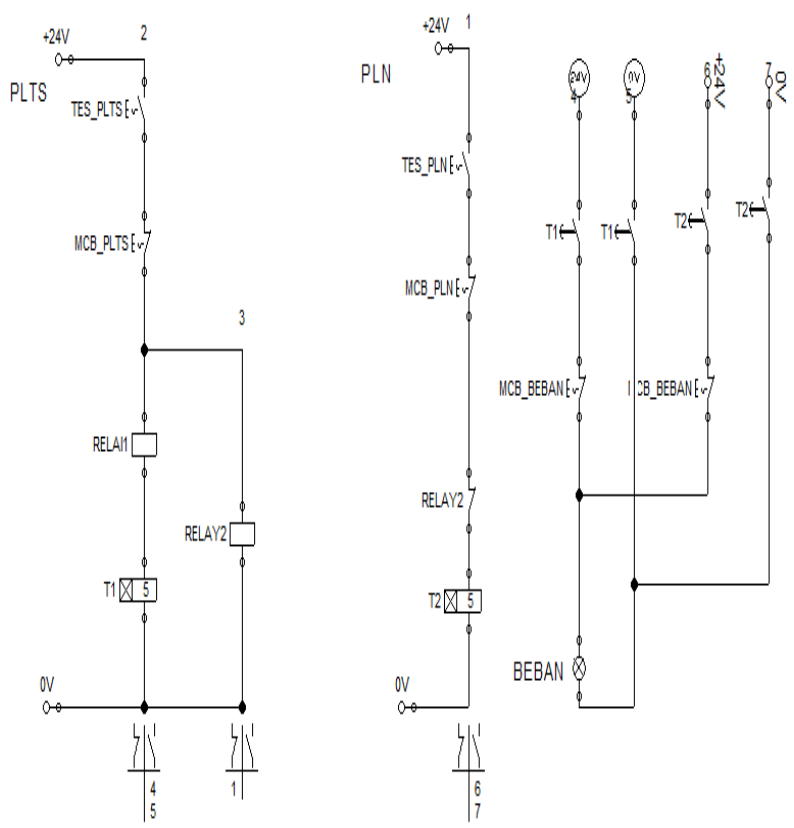

Fig. 7. Diagram of ATS system in Festo fluidSIM software

In this study, three ATS performance testing schemes were carried out, as shown in Fig. 8, Fig. 9, and Fig. 10. Fig. 8 shows the diagram of ATS system in Festo fluidSIM software, which the first simulation for automatic control of SHS-on and PLN-off. Fig. 9 shows the diagram of ATS system in Festo fluidSIM software, which the second simulation for automatic control of SHS-off and
PLN-on. Fig. 10 shows the diagram of ATS system in Festo fluidSIM software, which the third simulation for automatic control of interlock system. All three test schemes have been implemented perfectly. The test results are shown in Table I.
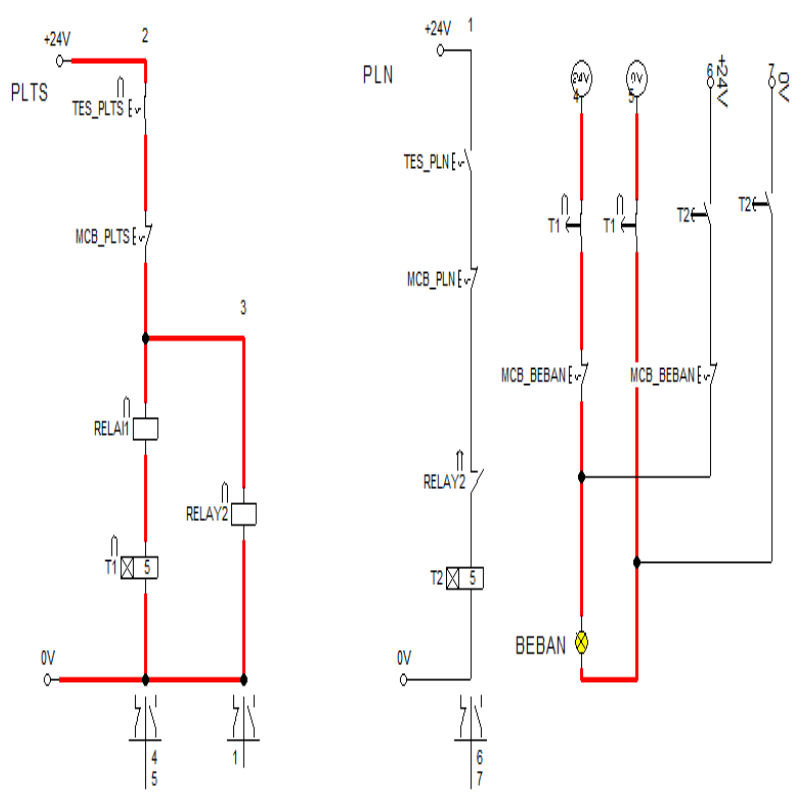

Fig. 8. Diagram of ATS system in Festo fluidSIM software: first simulation for automatic control of SHS-on and PLN-off
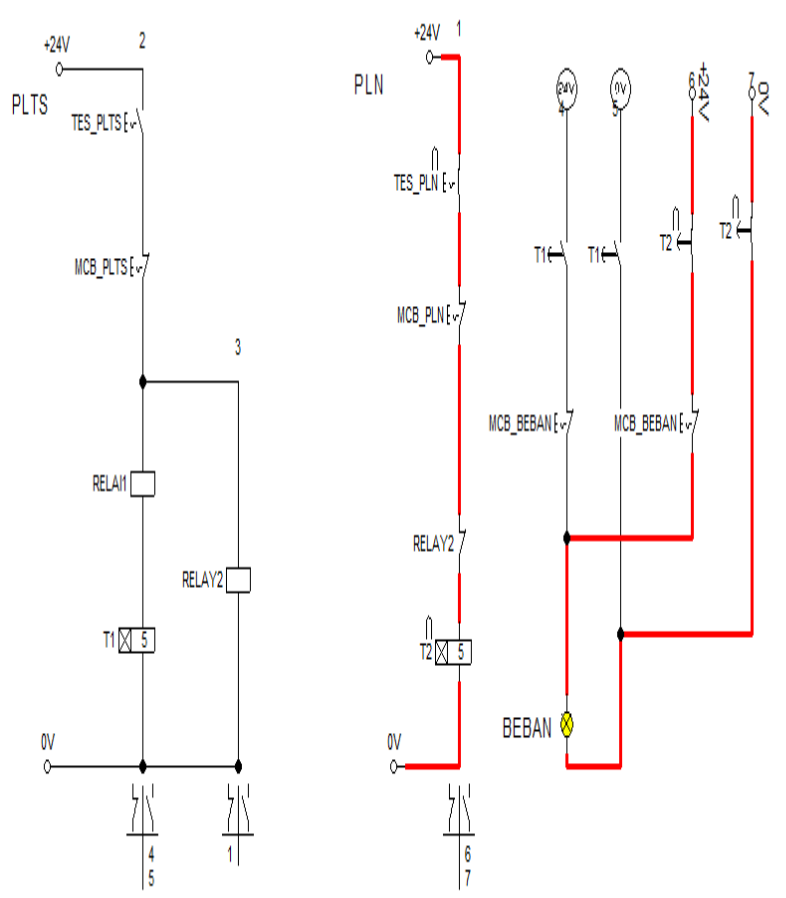

Fig. 9. Diagram of ATS system in Festo fluidSIM software: second simulation for automatic control of SHS-off and PLN-on 

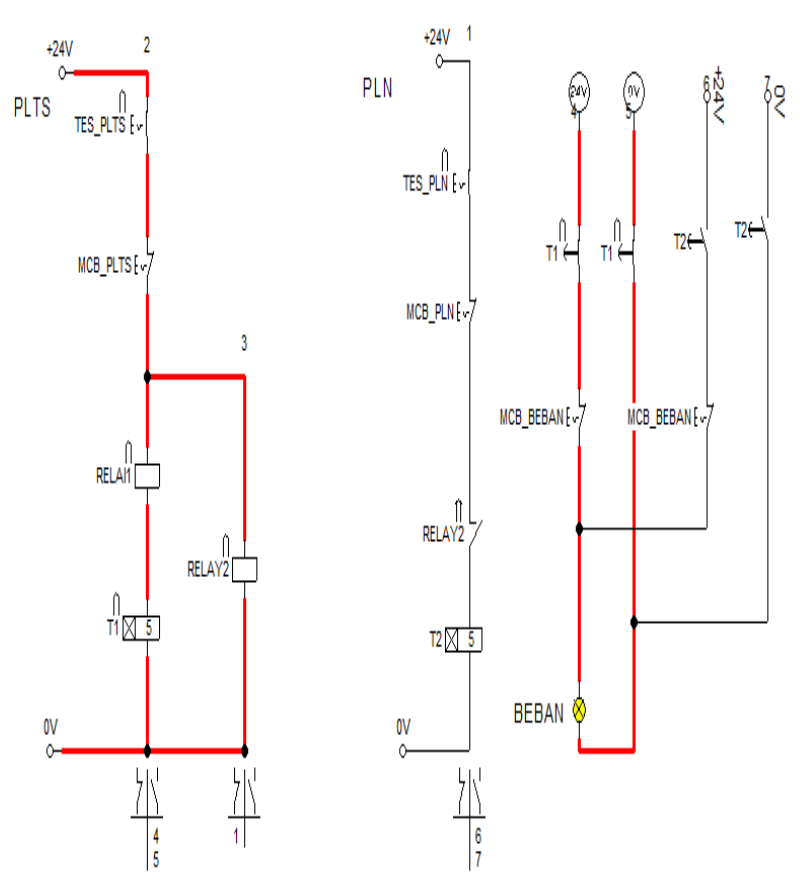

Fig. 10. Diagram of ATS system in Festo fluidSIM software: third simulation for automatic control of interlock system

Figure 7 shows the initial circuit image before simulation. In this circuit, there is a slight difference with the wiring circuit diagram. The difference lies in the SHS test component and the PLN test on the original circuit conditions that do not exist. It is made for simulation purposes as a switch for disconnecting and connecting energy sources. The power source used is also different from the actual conditions of the 220v source used. However, because it is only used as a simulation, the source used is a voltage source of $24 \mathrm{~V}$, relay 1 , and relay 2 . The simulation circuit can be interpreted as a condition on the relay, namely, relay 1 as normally close while relay 2 as normally open.

The following are the conditions that occur in the system when the simulation is carried out:

1) The SHS condition is on, and PLN is in a dead condition, and the load is on with the energy source obtained from the SHS.

2) When the SHS is off, and PLN is on, the load turns on with energy sourced from PLN.

3) the condition of the SHS is on, and the PLN is on, the load is live with the energy source obtained from the SHS. This proves that the system is designed using a priority system.

4) The last condition, when the SHS is off, and PLN is off, the load does not turn on. This condition is because, in addition to regulating the work source to flow to the load, ATS also functions to connect energy sources if the two energy sources do not work, the ATS system also does not function.

TABLE I

ATS SYSTEM TEST RESULTS IN VARIOUS SCENARIOS

\begin{tabular}{|c|c|c|c|c|c|c|c|c|}
\hline \multirow{2}{*}{ ATS Test Conditions } & \multicolumn{2}{|c|}{ TDR Position } & \multicolumn{2}{|c|}{ Indicator Lamp Position } & \multicolumn{4}{|c|}{ LED Lamp Load Position } \\
\hline & SHS & PLN & SHS & PLN & $10 \mathrm{~W}$ & $10 \mathrm{~W}$ & $10 \mathrm{~W}$ & $10 \mathrm{~W}$ \\
\hline SHS-on and PLN-off & 1 & 0 & 1 & 0 & 1 & 1 & 1 & 1 \\
\hline SHS-off and PLN-on & 0 & 1 & 0 & 1 & 1 & 1 & 1 & 1 \\
\hline SHS-on and PLN-on & 1 & 0 & 1 & 0 & 1 & 1 & 1 & 1 \\
\hline SHS-off and PLN-off & 0 & 0 & 0 & 0 & 0 & 0 & 0 & 0 \\
\hline
\end{tabular}

Table 1 shows the results of the tests carried out from the SHS line to PLN. The trial was carried out with 3 experiments on each data taken, and for each data, a predetermined time was taken. In different TDR conditions, there is a difference between the time set in the TDR and the time measured at the stopwatch. The difference in the 2 nd and 5th data from the first experiment in each data is not too far from the results set in the TDR. This is due to the late pressing of the stopwatch button so that there is a gap between the time set in the TDR and the time measured on the stopwatch.

In contrast to the results of experiments, it is confirmed that have been carried out by moving from SHS to PLN. In the experiments that have been carried out to test the transfer from PLN to SHS that there is no difference between the time set in the TDR and the time measured on the stopwatch, this experiment was carried out the same as the experiment in Table 1 uses the same amount of load 
and time. From the results of the overall displacement experiment, it was found that the system created was good and by what was designed at the beginning of the process of designing this Automatic Transfer Switch system.

\section{Conclusion}

Based on the automatic transfer switch (ATS) design that has been done, there are several conclusions in the process and system design results. The ATS system device can adequately regulate the transfer or source of energy automatically. When the primary energy source, namely SHS, is on, the load will be supplied by the primary source, but when the main source is turned off, the load will be supplied by a secondary energy source, namely PLN. When the primary energy source turns back on, the switch will move the energy source to the primary source, SHS.

From the ATS panel design results, several suggestions can be considered to produce a quality system, safe and following what is needed. In making the tool, each component should be tested first so that the components to be used are good and as expected. The box design process must be measured with precision first so that the results can be tidier and pay attention to the placement of the components so that they are not wrong or upside down. They are looking for component references with the same function to be compared to get the suitable component.

\section{References}

[1] A. Amin, A. Sultana, J. Hasan, M. T. Islam and F. Khan, "Solar home system in Bangladesh: Prospects challenges and constraints", 2014 3rd International Conference on the Developments in Renewable Energy Technology (ICDRET), pp. 1-5, 2014.

[2] B. S. Kumar and K. Sudhakar, "Performance evaluation of $10 \mathrm{MW}$ grid connected solar photovoltaic power plant in india", Energy Reports, vol. 1, pp. 184-192, 2015.

[3] N. Narayan, A. Chamseddine, V. Vega-Garita, Z. Qin, J. Popovic-Gerber, P. Bauer, et al., "Exploring the boundaries of Solar Home Systems (SHS) for offgrid electrification: Optimal SHS sizing for the multitier framework for household electricity access", Applied energy, vol. 240, pp. 907-917, 2019.

[4] D. Lee and K. Kim, "Recurrent neural network-based hourly prediction of photovoltaic power output using meteorological information", Energies, vol. 12, no. 2, pp. 215, 2019.

[5] V. F. Sivokobilenko and S. V. Derkachov, "Method for increasing of automatic transfer switch",
Electrical Engineering and Power Engineering, vol. 1, pp. 61-67, 2014.

[6] M. Q. Azeem, S. Ahmed and A. Khattak, "Design and analysis of switching in automatic transfer switch for load transfer", 2016 International Conference on Open Source Systems and Technologies (ICOSST), pp. 129-134, December 2016.

[7] V.I. Antonov, A.A. Il'in and N.M. Lazareva, "Adaptive structural models of input signals to relay protec tion and automation", Russ. Electr. Eng., vol. 83, no. 1, pp. 51, 2012.

[8] V. Naumov, V. I. Antonov, A. I. Fomin and A. V. Soldatov, "Adaptive structural analysis of input signals of digital and relay protection and automation", Russ. Electr. Eng., vol. 86, no. 7, pp. 391-397, 2015.

[9] S. Saputro. 2015. Rancangan bangun pembuatan alat panel listrik ATS (automatic transfer switch) - AMF (automatic main falure). Teknik Elektro. Universitas Negeri Jakarta.

[10] A. Majid. 2018. Perancangan sistem automatic transfer switch (ATS) sebagai komponen pelengkap sistem hybrid PLN - Sel Surya. Fakultas Teknik Universitas Muhammadiyah Palembang.

[11] K. Hidayat, 2013. Perancangan ATS (automatic transfer switch) satu phasa dengan batas daya peanggan maksimum 4400 VA. Teknik Elektro Universitas Bung Hatta Padang.

[12] Asriyadi, 2016. Rancang bangun automatic transfer switch (ATS) pada PLTS dan PLN serta Genset. Teknik Elektro Politeknik Negeri Ujung Pandang.

\section{Authors' information}

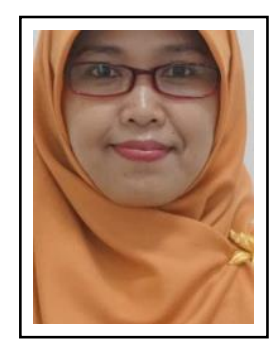

Anna Nur Nazilah Chamim received B.Sc. degree from Universitas Muhammadiyah Yogyakarta in 2001, and M.Eng. degree from Department of Electrical Engineering, Universitas Gadjah Mada, Yogyakarta, Indonesia in 2014.

Anna Nur Nazilah Chamim, M.Eng is a Lecturer in Department of Electrical Engineering, Faculty of Engineering, Universitas Muhammadiyah Yogyakarta, Indonesia. Her research interests are in image processing, telecommunication system, application of electronics, application of control system, and signal processing.

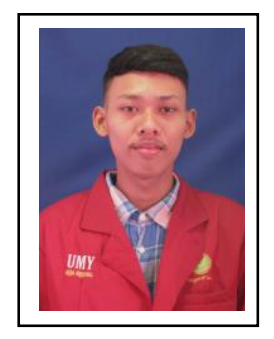

Agil Peggy Irawan received B.Sc. degree from Department of Electrical Engineering, Universitas Muhammadiyah Yogyakarta, Yogyakarta, Indonesia, in 2020.

His research interests are in electrical power system and renewable energy. 


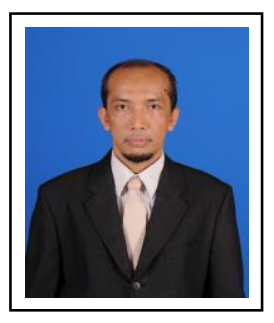

Ramadoni Syahputra received Ph.D degree at the Department of Electrical Engineering, Faculty of Industrial Technology, Institut Teknologi Sepuluh Nopember in 2015.

Dr. Ramadoni Syahputra is a Lecturer in Department of Electrical Engineering, Universitas Muhammadiyah Yogyakarta, Indonesia. His research interests are in artificial intelligence in power system, computational of power system, power system control, fuzzy logic in power system, optimization, and renewable energy. 